\title{
Preparation of Telechelic Oligomers by the Thermal Degradation of Syndiotactic Polypropylene
}

\author{
Takashi SAWAGUCHI $^{\dagger}$ and Manabu SENO \\ Department of Industrial Chemistry, College of Science and Technology, Nihon University, \\ Kandasurugadai, Chiyoda-ku, Tokyo 101, Japan
}

(Received March 14, 1996)

\begin{abstract}
KEY WORDS Telechelics / Syndiotactic Polypropylene / End-Reactive Oligomer / Isopropenyl End Group / Vinylidene Double Bond /
\end{abstract}

Terminal-functionalized polyolefins are useful for the synthesis of block copolymers and modifications of polymer properties. Some attempts have been made to prepare of these polymers. Some end-reactive polypropylenes are synthesized by utilizing the living active end of almost uniform syndiotactic polypropylene prepared by living polymerization with soluble vanadiumbased catalysts. ${ }^{1}$ Recently, the Kaminsky-type homogeneous catalyst was found active for the synthesis of polypropylenes with completely different stereoregularities depending on the kind of organotransition-metal complex. $^{2}$ The polymer prepared by this method of polymerization has a terminal vinylidene double bond ${ }^{3}$ and thereby some terminal-functionalized polypropylenes are prepared by reactions of the isopropenyl end group. ${ }^{4}$ However, these reactive polymers possess a functional group not at both chain end but at one chain end.

More recently, we found that almost all nonvolatile oligomers isolated from the polymer residue by the thermal degradation of isotactic polypropylene at $370^{\circ} \mathrm{C}$ are $\alpha, \omega$-diene-oligomers having two isopropenyl groups at both chain ends. ${ }^{5}$ These oligomers are expected to be useful as new telechelic oligomers, since they retain the stereoregularity (microtacticity) of the original polymer.

The physical properties of highly syndiotactic polypropylene with a relatively low crystallinity prepared by a Kaminsky-type homogeneous catalyst markedly differ from those of isotactic polypropylene. ${ }^{6}$

This note demonstrates that syndiotactic $\alpha, \omega$-dieneoligomers are prepared by the thermal degradation of syndiotactic polypropylene.

\section{EXPERIMENTAL}

\section{Sample}

The syndiotactic polypropylene used was "SPT-0071" supplied by Mitsui Toatsu Chemicals, Inc. and used without further purification. Characteristics of the sample are shown in Table I.

\section{Apparatus}

The apparatus and procedure for thermal degradation are described in detail in a previous paper. ${ }^{5}$ After the reaction, the polymer residue in the flask was dissolved

\footnotetext{
† To whom correspondence should be addressed.
}

in $10 \mathrm{~cm}^{3}$ of xylene and reprecipitated with $50 \mathrm{~cm}^{3}$ of 2-propanol to remove small amounts of volatile oligomers. The reprecipitates were termed nonvolatile oligomers and used as samples for characterization after vacuum drying under heating.

\section{Characterization}

${ }^{13} \mathrm{C}$ NMR spectra were measured with a JEOL JNMGX400 spectrometer operated at $100.40 \mathrm{MHz}$ and $110^{\circ} \mathrm{C}$ with an internal lock. The protons were decoupled from the carbon nuclei using a random noise decoupling field. The concentration of the sample was approximately $10 \%$ $(\mathrm{w} / \mathrm{v})$ in a $2: 1(\mathrm{v} / \mathrm{v})$ mixture of 1,2,4-trichlorobenzene and benzene- $d_{6}$. Hexamethyldisiloxane (HMDS) was used as the internal standard $(2.0 \mathrm{ppm}$ from tetramethylsilane, $\mathrm{Me}_{4} \mathrm{Si}$ ). Pulse angle of $90^{\circ}$ and pulse repetition times of $16.363 \mathrm{~s}$ were used. Measurement was generally carried out for about $50 \mathrm{~h}$. These conditions promised that the equilibrium magnetization was attained and saturation of resonance of interest would not occur. ${ }^{1} \mathrm{H}$ NMR spectra were also measured with a JEOL JNMGX400 spectrometer operated at $399.65 \mathrm{MHz}$ and $110^{\circ} \mathrm{C}$ with internal lock. Pulse angle of $45^{\circ}$ with a pulse repetition of $22.81 \mathrm{~s}$ and about 1000 scans were used. The intensities of the peaks in ${ }^{1} \mathrm{H}$ and ${ }^{13} \mathrm{C}$ NMR spectra were measured by the area method.

$M_{n}, M_{w}$ and molecular weight distribution were measured by a GPC (SSC-7100). The data were calibrated by standard polystyrene, and $26.4^{7}$ was used as the $Q$ factor without intrinsic viscosity measurement. The melting point $\left(T_{\mathrm{m}}\right)$ and heat of melting $(\Delta H)$ were measured by DSC (Seiko DSC 220) in a stream of $\mathrm{N}_{2}$ gas. Measurement conditions were as follows: sample weight, ca. $10 \mathrm{mg}$; heating rate, $5.0^{\circ} \mathrm{C} \mathrm{min}^{-1}$.

\section{RESULTS AND DISCUSSION}

Yield of the polymer residue and characteristics of the nonvolatile oligomers obtained by the thermal degradation of syndiotactic polypropylene at $370^{\circ} \mathrm{C}$ are listed in Table I. GPC curves of the original polymer and nonvolatile oligomers are shown in Figure 1. Mn of the nonvolatile oligomers ranged from 3000 to 3500 and the $M_{w} / M_{n}$ ratio markedly decreased to $c a .2$ from 4.18 of the original sample. The microtacticity (triad) of the nonvolatile oligomers is nearly the same as that of the original polymer, that is, the nonvolatile oligomers 
Table I. Yeild of polymer residue and characteristics of nonvolatile oligomers obtained by the thermal degradation of syndiotactic polypropylene at $370^{\circ} \mathrm{C}$

\begin{tabular}{|c|c|c|c|c|c|c|c|c|c|c|c|}
\hline \multirow{3}{*}{$\begin{array}{l}\text { Time } \\
\min \end{array}$} & \multirow{3}{*}{$\frac{\text { Yield }}{\text { wt } \%}$} & \multicolumn{10}{|c|}{ Nonvolatile oligomers } \\
\hline & & \multirow{2}{*}{$M_{w} \times 10^{-3}$} & \multirow{2}{*}{$M_{n} \times 10^{-3}$} & \multirow{2}{*}{$\frac{M_{w}}{M_{n}}$} & \multirow{2}{*}{$\frac{M_{n 0}}{M_{n}}-1$} & \multicolumn{3}{|c|}{ Microtacticity (triad) ${ }^{\mathrm{a}}$} & \multirow{2}{*}{$\frac{T_{\mathrm{m}}}{{ }^{\circ} \mathrm{C}}$} & \multirow{2}{*}{$\frac{\Delta H}{\mathrm{Jg}^{-1}}$} & \multirow{2}{*}{$\begin{array}{c}\text { Functionality, } \\
f_{t}\end{array}$} \\
\hline & & & & & & $m m$ & $m r$ & $r r$ & & & \\
\hline 0 & 0 & 233 & 55.8 & 4.18 & - & 0.04 & 0.18 & 0.78 & 128.2 & 26.4 & - \\
\hline 30 & 90 & 13.6 & 4.59 & 2.97 & 11.1 & 0.04 & 0.08 & 0.88 & 131.9 & 48.9 & 1.76 \\
\hline 60 & 78 & 8.51 & 3.52 & 2.42 & 14.8 & 0.04 & 0.12 & 0.84 & 127.5 & 53.3 & 1.78 \\
\hline 90 & 65 & 6.38 & 3.20 & 1.99 & 16.5 & 0.05 & 0.12 & 0.83 & 124.8 & 67.7 & 1.72 \\
\hline
\end{tabular}

${ }^{a}$ Determined from the relative intensity of triad peaks of methyl carbon except for peaks of each end group in the ${ }^{13} \mathrm{C} \mathrm{NMR}$ spectrum. b $2 \times I_{\mathrm{TUD}} /\left[I_{\mathrm{TUD}}+I_{n-\mathrm{pr}}\right]$; I: Intensity of the ${ }^{13} \mathrm{C}$ NMR methyl signal of each end group.

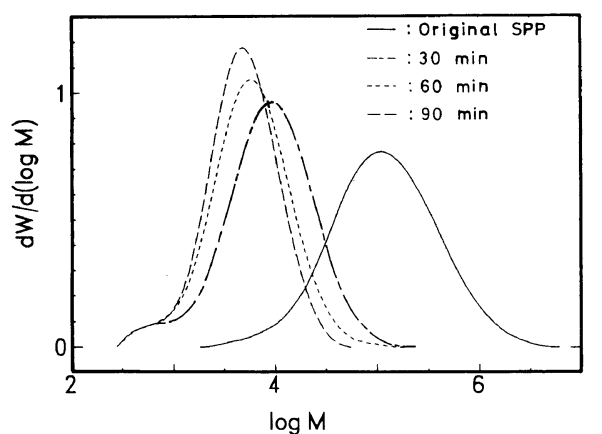

Figure 1. GPC curves of the original polypropylene and nonvolatile oligomers.

mostly retain the stereoregularity of the original polymer without random epimerization during thermal degradation. A relatively broad endothermic peak of DSC curve, possibly caused by melting of crystallites, increased largely for the oligomers compared to the original polymer. As shown in Table I, the melting point $\left(T_{\mathrm{m}}\right)$ slightly reduces from $128^{\circ} \mathrm{C}$ for the original polymer to $c a .125^{\circ} \mathrm{C}$ for the oligomers. The right column of Table I represents the average number of isopropenyl end groups per molecule $\left(f_{t}\right)$.

Portions of ${ }^{13} \mathrm{C}$ and ${ }^{1} \mathrm{H}$ spectra of the nonvolatile oligomers are shown in Figures 2 and 3, respectively. Characteristic signals in these figures are extremely similar to those of end groups of the nonvolatile oligomers prepared from isotactic polypropylene. ${ }^{5}$ According to identification of these end groups, ${ }^{5}$ a signal at 20.52 ppm in Figure 2 was exactly assigned to $\alpha$ methyl carbon $^{3,8,9 d}$ of the terminal vinylidene double bond (TVD) of isopropenyl end group $\left[\mathrm{CH}_{2}=\mathrm{C}\left(\mathrm{CH}_{3}\right)^{-}\right]$and the resonances at 109.64 and $142.57 \mathrm{ppm}$ were assigned to the olefinic carbons of TVD. ${ }^{3,8,9 d}$ No signal corresponding to the internal olefinic carbons was detected. Two strong signals around 4.601 and $4.661 \mathrm{ppm}$ and a very weak signal around $5.262 \mathrm{ppm}$ were recognized in the ${ }^{1} \mathrm{H}$ NMR spectrum of each nonvolatile oligomer (Figure 3 ). These two strong signals were assigned to two nonequivalent olefinic protons of $\operatorname{TVD}^{4 c-f, 9 d}$ and the very weak signal may be due to one olefinic proton of the internal double bond. ${ }^{9}$ The contents of these double bonds are about $95 \mathrm{~mol} \%$ of the former and about $5 \mathrm{~mol} \%$ of the latter. The signals at 12.46 and 38.71 ppm in Figure 2 correspond to methyl and methylene carbons from the end of the $n$-propyl group ( $n$-Pr) $\left[\mathrm{CH}_{3} \mathrm{CH}_{2} \mathrm{CH}_{2} \mathrm{CH}\left(\mathrm{CH}_{3}\right)^{-}\right]$, respectively, and the signals at $38.71 \mathrm{ppm}$ was assigned to the tetrad ( $r r r, r$ : racemo) methylene carbons. ${ }^{3,9}$ Because no resonance was detected at 20.4, 20.6, 21.4, 21.7, and $24.0 \mathrm{ppm}$ as shown in Figure $2,{ }^{9}$ the existence of isopropyl end group is negligible. The methyl carbon resonance is sensitive to the configuration of polymer chain ${ }^{11 \mathrm{a}}$ and most of the resonance between $18.00-19.85 \mathrm{ppm}$ was assigned to the pentad and heptad configurational sequence of methyl carbon. ${ }^{9 \mathrm{c}, \mathrm{d}}$ Consequently, both TVD and $n$-Pr were detected only in the nonvolatile oligomers isolated from the polymer residues resulting from the thermal degradation of syndiotactic polypropylene.

The intensities of signals of $\alpha$ methyl carbon $(20.52$ ppm) of TVD and methyl carbon (12.46 ppm) of $n$-Pr in Figure 2 were measured by the area method. The results show certainly that the end groups of the nonvolatile oligomers consist of about $88 \mathrm{~mol} \%$ of isopropenyl group (TVD) and about $12 \mathrm{~mol} \%$ of $n$-Pr. Assuming all nonvolatile oligomers are linear, $f_{\mathrm{t}}$ was calculated as 1.76 from the following equation ${ }^{5}$

$f_{\mathrm{t}}=$

$\frac{2 \times\left(\text { methyl signal intensity of isopropenyl end group, } I_{\mathrm{TVD}}\right)}{\left.\text { (methyl signal intensity of all end groups, }\left[I_{\mathrm{TVD}}+I_{n-\mathrm{Pr}}\right]\right)}$

This $f_{\mathrm{t}}$ indicates that about $77 \mathrm{~mol} \%$ of the oligomer molecules is a structurally symmetric $\alpha, \omega$-diene-oligomer having two isopropenyl end groups. The contents of macromonomers having an isopropenyl end group and an $n$-Pr end group and the terminal-saturated oligomer having two $n$-Pr groups are about $21 \mathrm{~mol} \%$ and $2 \mathrm{~mol} \%$, respectively. These values were derived by statistical fitting, as described previously. ${ }^{5}$ As suggested from changes in GPC curves (Figure 1), the scission reaction of the main chain occurs at random positions of the polymer. Average numbers of scission $\left(M_{n 0} / M_{n-1}\right)$ are 11,15 , and 17 after 30,60 , and $90 \mathrm{~min}$ at $370^{\circ} \mathrm{C}$, respectively. Therefore, over $92 \%$ of the end groups of these oligomers are formed during scission reactions.

Thus, it was concluded that syndiotactic telechelic oligopropylenes having two isopropenyl end groups could be synthesized in good yield by the thermal degradation of syndiotactic polypropylene. These oligomers are also expected as new telechelic oligomers. ${ }^{5}$ We prepared multiblock copolymers of $\alpha, \omega$-dihydrosilylpolydimethylsiloxane with these telechelic oligomers with different stereoregularities. ${ }^{12}$

The degradation products are produced via various elementary reactions of secondary terminal macro- 


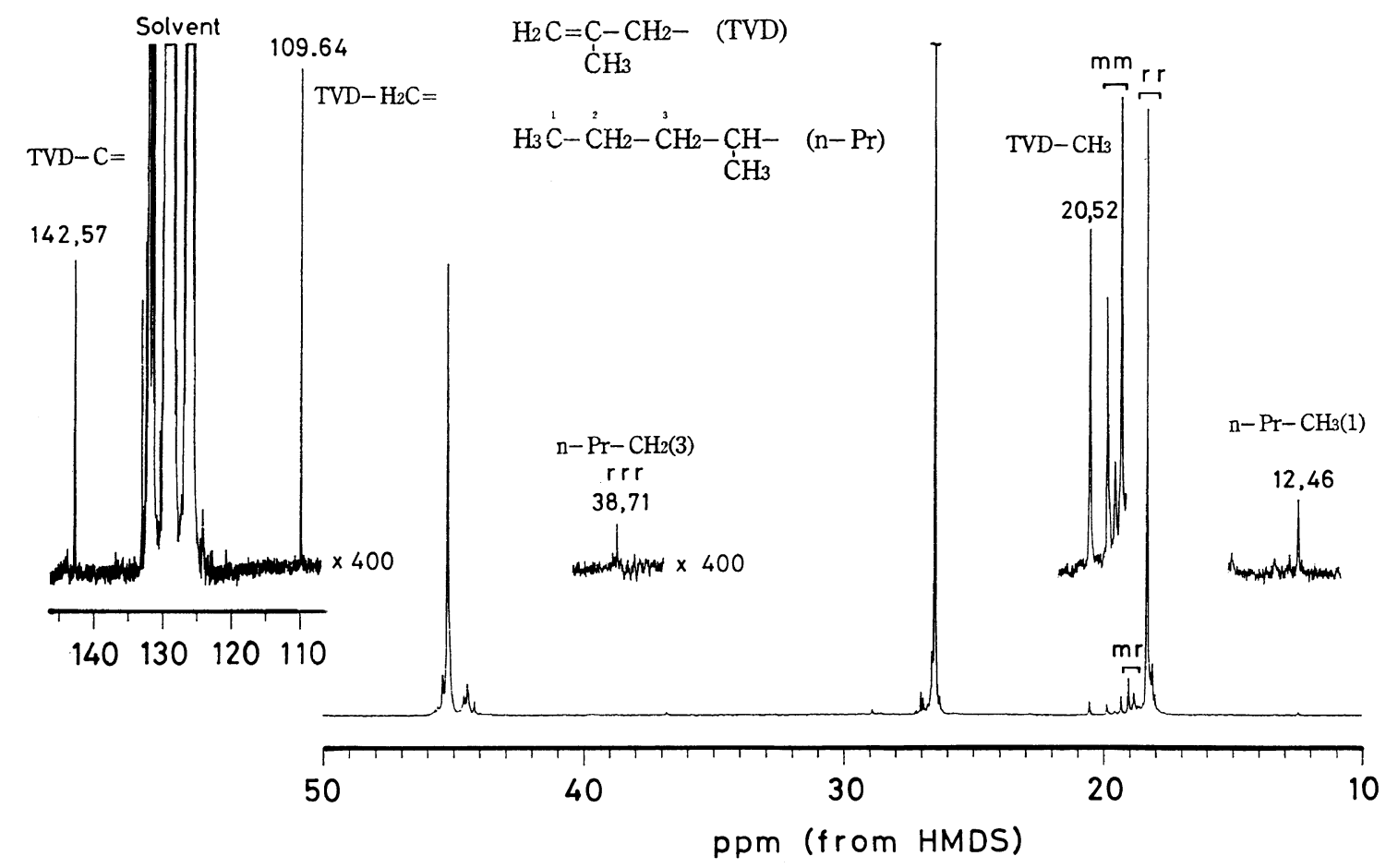

Figure 2. A portion of ${ }^{13} \mathrm{C}$ NMR spectra of the nonvolatile oligomers.

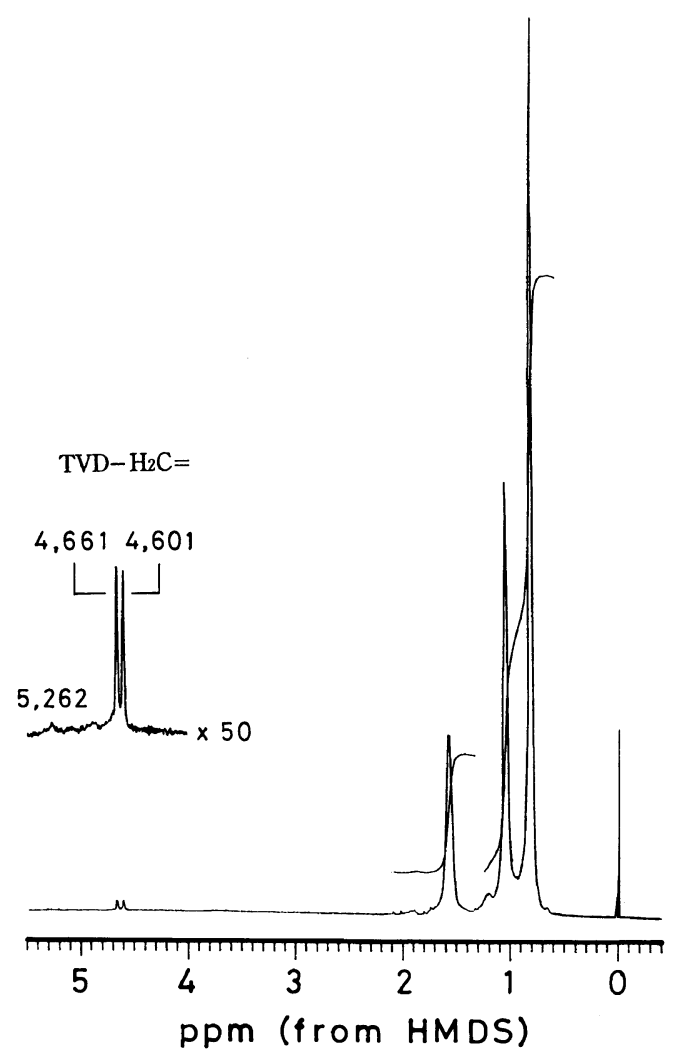

Figure 3. A portion of ${ }^{1} \mathrm{H}$ NMR spectra of the nonvolatile oligomers.

radicals in the depropagation step, as discussed previously. ${ }^{5} \mathrm{~A}$ possible mechanism for the predominant formation of TVD of nonvolatile oligomers (polymer residue) is as follows: telechelic oligomers are formed by intramolecular hydrogen abstraction (back-biting) of secondary terminal macroradicals followed by $\beta$ scission at the end of main chain and intermolecular hydro- gen abstraction of secondary terminal volatile radicals formed by the back-biting and other elementary reactions, followed by $\beta$ scission.

Acknowledgments. The authors wish to express their gratitude to Mr. Inoue of Mitsui Toatsu Chemicals, Inc. for supplying the syndiotactic polypropylene sample, and Mr. Kimura of Japan Vilene Co., Ltd. for GPC measurements.

\section{REFERENCES}

1. For example: (a) Y. Doi, S. Ueki, and T. Keii, Macromolecules, 12, 814 (1979); (b) Y. Doi, S. Ueki, and T. Keii, Makromol. Chem., 180, 1359 (1979); (c) Y. Doi, F. Nozawa, M. Murata, S. Suzuki, and K. Soga, Makromol. Chem., 186, 1825 (1985); (d) Y. Doi, M. Murata, and K. Soga, Makromol. Chem., Rapid Commun., 5, 811 (1984); (e) Y. Doi, T. Koyama, and K. Soga, Makromol. Chem., 186, 11 (1985); (f) Y. Doi, G. Hizal, and K. Soga, Makromol. Chem., 188, 1273 (1987); (g) Y. Doi, M. Nunomura, N. Ogizawa, and K. Soga, Makromol. Chem., Rapid Commun., 12, 245 (1991).

2. For example: (a) Chem. Eng. News, July 4, 29 (1983); (b) W. Kaminsky, K. Kuper, H. H. Brintzinger, and F. R. W. P. Wild, Angew. Chem. Int., Engl., 24, 507 (1985); (c) J. A. Ewen, R. L. Jones, and A. Razavi, J. Am. Chem. Soc., 110, 6255 (1988).

3. T. Tsutsui, A. Mizuno, and N. Kashiwa, Polymer, 30, 428 (1989).

4. For example: (a) R. Mülhaupt, T. Duschek, and B. Rieger, Makromol. Chem., Macromol. Symp., 48/49, 317 (1991); (b) T. Duschek and R. Mülhaupt, Polym. Prepr., Am. Chem. Soc., Div. Polym. Chem., 33, 170 (1992); (c) T. Shiono and K. Soga, Macromolecules, 25, 3356 (1992); (d) T. Shiono, H. Kurosawa, O. Ishida, and K. Soga, Koubunshi Ronbunshu, 49, 847 (1992); (e) T. Shiono and K. Soga, Makromol. Chem., Rapid Commun., 13, 371 (1992); (f) T. Shiono, H. Kurosawa, O. Ishida, and K. Soga, Macromolecules, 26, 2085 (1993); (g) R. Mülhaupt, T. Duschek, D. Fischer, and S. Setz, Polym. Adv. Technol., 4, 439 (1993); (h) R. Mülhaupt, T. Duschek, and J. Rosch, Polym. Adv. Technol., 4, 465 (1993); (i) T. Shiono, Y. Akino, and K. Soga, Macromolecules, 27, 6229 (1994).

5. T. Sawaguchi, T. Ikemura, and M. Seno, Macromolecules, 28, 7973 (1995). 
6. (a) R. Sugimoto, Kagaku to Kogyo, 46, 1097 (1993); (b) T. Shiomura, M. Kohno, N. Inoue, T. Asanuma, R. Sigimoto, T. Iwatani, O. Uchida, S. Kimura, S. Harima, H. Zenkoh, and E. Tanaka, Macromol. Symp., 101, 289 (1996).

7. D. E. Ouano and P. L. Mercier, J. Polym. Sci., Part C, 21, 315 (1968).

8. S. Nemes, J. Borbely, J. Borda, and T. Kelen, Polym. Bull., 28, 633 (1992).

9. (a) A. Zambelli, P. Locatelli, and E. Rigamonti, Macromolecules, 12, 156 (1979); (b) A. Zambelli, P. Locatelli, and G. Bajo, Macromolecules, 12, 154 (1979); (c) T. Hayashi, Y. Inoue, R. Chujo, and T. Asakura, Macromolecules, 21, 2675 (1988); (d) T.
Hayashi, Y. Inoue, R. Chujo, and Y. Doi, Macromolecules, 30, 1714 (1989).

10. J. Furukawa, S. Tsuruki, and J. Kiji, J. Polym. Sci., Polym. Chem. Ed., 11, 2999 (1977)

11. (a) A. E. Tonelli, "NMR Spectroscopy and Polymer Mictostructures: The Conformational Connection," VCH Publishers, New York, N.Y., 1989; (b) J. C. Randall, J. Polym. Sci., Polym. Phys. Ed., 14, 1693 (1976); "Polymer Sequence Distribution Carbon-13 NMR Method," Academic Press, New York, N.Y., 1977.

12. T. Sawaguchi and M. Seno, J. Polym. Sci., Polym. Chem. Ed., submitted. 